NBER WORKING PAPER SERIES

TOWARDS A RECONSTRUCTION OF KEYNESIAN ECONOMICS: EXPECTATIONS AND CONSTRAINED EQUILIBRIA

\author{
J. Peter Neary
}

Joseph E. Stiglitz

Working Paper No. $\underline{376}$

\author{
NATIONAL BUREAU OF ECONOMIC RESEARCH \\ 1050 Massachusetts Avenue \\ Cambridge MA 02138 \\ August 1979
}

The research reported here is part of the NBER's research program in Business Taxation and Finance. Any opinions expressed are those of the authors and not those of the National Bureau of Economic Research. 


\section{Towards a Reconstruction of Keynesian Economics: Expectations and Constrained Equilibria}

\section{ABSTRACT}

A two-period model of temporary equilibrium with rationing is presented, paying particular attention to agents' expectations of future constraints. It is shown that with arbitrary constraint expectations many different types of current equilibria may be consistent with the same set of (current and expected future) wages and prices, and that constraint expectations tend to be self-fulfilling (e.g., a higher expectation of Keynesian unemployment tomorrow increases the probability that it will prevail today). In addition, rational constraint expectations (i.e., perfect foresight of future constraint levels) are shown to enhance rather than reduce the effectiveness of government policy.

J. Peter Neary

Department of Economics

M.I.T.

Cambridge, MA 02139
Professor Joseph E. Stiglitz

Institute of Economics and Statistics

University of oxford

St. Cross Building

Manor Road

Oxford, England oxl 3UL 
TOWARDS A RECONSTRUCTION OF KEYNESIAN ECONOMICS:

\section{EXPECTATIONS AND CONSTRAINED EQUILIBRIA}

\section{INTRODUCTION}

This paper provides an old answer to an old question: how can we explain unemployment equilibria? The answer, provided both by Keynes and by more recent equilibrium analysts, is that there is some rigidity in prices (of factors or commodities) in the economy. It is well known that, if all prices are flexible, equilibrium will be characterized by full employment of all factors (which are not in absolute surplus). Although the precise articulation of the nature of equilibrium when prices are not flexible (Hansen (1951), Solow and Stiglitz (1968), Hicks (1974), Benassy (1975), Grandmont (1977)), including the derivation of demand and supply curves when participants are constrained in their purchases and/or sales of factors and commodities (Patinkin (1965), Clower (1965), Leijohnufvud (1968), Barro and Grossman (1971), Malinvaud (1977)) is of a more recent vintage, the basic insight that when there is a rigidity in some factor or commodity price then the only equilibria will entail rationing in some markets, remains unaltered ${ }^{1}$. 
That leaves two critical questions to be answered if we are to understand the nature of unemployment in our economy: which prices are rigid, and why are they rigid. The recent works of Barro and Grossman and Malinvaud do not attempt to answer the latter question; they simply posit that money wages and prices are rigid. We provide an alternative answer to these questions: because of the absence of futures markets, individuals must base their current decisions on expectations; for certain expectations, there may be no values of current variables (wages and prices today) at which labor is fully employed. ${ }^{2}$

More generally, it is our belief that the short-run analysis of Malinvaud, Barro-Grossman and Solow-Stiglitz misses out an essential part of the Keynesian story: the role of savings and investment, interest rates and expectations. We show that the constraints which households and firms expect to face in the future are critical in determining their current behaviour. A major implication of this approach is that it becomes very likely that there exist multiple selffulfilling expectational equilibria, e.g. if households expect that they will be unable to sell all their labor both this period and next, then in fact, it will turn out that they will be unable to sell all their labor; but had they expected there to be inflationary pressures this period and next, then that might indeed turn out to be the case instead. 
Even more surprising is the result that there may exist temporary equilibria which exhibit unemployment or excess demand for labour when expectations are rational (where we use the term rational expectations in the conventional sense, that agents possess full information now, not only about the prices, but also about the constraints, not only qualitatively, but quantitatively, which they will face in the future). The paper thus serves to clarify the distinctive roles played by the assumptions of rational expectations and price flexibility in some recent models of macro-economic equilibrium: rational expectations are consistent both with full employment and unemployment equilibria; it is perfect wage and price flexibility which is necessary (but not sufficient) to ensure full employment, in general.

The model we construct has policy implications which differ in some significant ways from those of the Barro-Grossman-Malinvaud oneperiod model as well as from those of the more recent rationalexpectations literature. The latter, for instance, has emphasized the inefficacy of government policy; we show, on the contrary, that having rational expectations actually results, in certain situations, in the multipliers associated with government fiscal policy being greater than they would be with, say, static expectations: an increase in government expenditure today has a spill-over effect in raising national income at a future date; if the equilibrium at that date is also a Keynesian (demand-constrained) equilibrium, then that increases the demand for labour at that date; the anticipation of this increased demand for labour reduces savings currently, and hence current aggregate demand rises. 
Our model also has different implications with respect to the effect of wage and price cuts. There is considerable evidence, for example, that the real wage did not vary significantly in the course of the great depression; assuming plausibly that the aggregate production function did not shift significantly during that period, this evidence would imply that the economy was at the Walrasian equilibrium real wage: According to the Barro-Grossman-Malinvaud analysis, "all" that was required in this situation was a proportionate reduction in wages and prices, which would have restored full employment by means of the real-balance effect. We argue, however, that these realbalance effects are quantitatively insignificant, and that the shortrun dynamics of expectations (and, after all, it is the short run with which we are concerned here) are such that reductions in wages and prices may actually exacerbate the unemployment. our model is thus much more in the tradition of Hansen and Solow-Stiglitz who questioned the relevance of the real-balance effect for short-run macro-economic analysis.

We believe that the model we have constructed, simple as it is, captures much of what was contained in Keynes, but seems so missing in the one-period macro-economic models, in which savings and investment, interest rates and expectation formation play no critical role.

The plan of the paper is as follows. In Section 2 we outline the micro-economic foundations of the model, illustrate the determination of notional equilibrium when all wages and prices are flexible, and examine the various types of effective equilibrium which can prevail 
when the current and expected future wage rate and the expected future output price are sticky. In this section we assume that agents have Walrasian expectations (i.e., they do not expect to face any quantity constraints in the future), while in Sections 3 and 4 we investigate the consequences of arbitrary and rational constraint expectations respectively. Section 5 considers the comparative statics properties of the model, while section 6 re-examines its behaviour when the current real wage is assumed to be perfectly flexible. Finally, Section 7 summarises the paper's conclusions and notes some directions for further research.

\section{NOTIONAL AND EFFECTIVE EQUILIBRIA WITH WALRASIAN EXPECTATIONS}

The model to be examined is a two-period one, in which agents base their behaviour in the present, period 1 , on their subjectively certain point expectations concerning prices, wages and constraint. levels in the future, period 2. Considering first the behaviour of households, we abstract from distribution effects, and so assume that the behaviour of the household sector can be characterized as if it were the outcome of the maximization of a single aggregate utility function. Since we assume for simplicity that total labour supply is fixed and since we are excluding a real-balance effect, utility depends on present and future consumption only. This is written in a simple additive form, where the discount factor $\alpha$ equals $\left(1+\delta_{H}\right)^{-1}$, $\delta_{H}$ being the household sector's discount rate: 


$$
\mathrm{U}=\mathrm{u}\left(\mathrm{c}_{1}\right)+\alpha u\left(c_{2}\right)
$$

When households are unconstrained, maximization of (1) is carried out subject to two budget constraints, the lifetime budget constraint (2) and the requirement (implied by the assumption of imperfect capital markets) that current consumption cannot exceed current income:

$$
c_{1}+p_{2} c_{2} \leq Y=\bar{m}+w_{1} L+w_{2} L
$$

$$
c_{1} \leq \bar{m}+w_{1} L
$$

where the current output price, $\mathrm{p}_{1}$, is normalized to equal unity, $\bar{m}$ is the value of the household's initial endowment, $L$ is the household's labour supply (assumed not to change between periods) and $w_{2}$ and $p_{2}$ are the present values of the currently expected future wage and price level respectively. ${ }^{3}$ Note that we assume that firms' profits are not redistributed to households, but instead are absorbed by the government through 100 per cent profits taxation. This is an undesirable assumption, both because it implies that government policy is state-dependent, and because, by assuming a zero propensity to consume out of profits, it leaves the model open to the criticism that it is biased in favour of fiscal policy. However, this assumption permits a considerable simplification of the model and it does not affect any of its qualitative properties. 
Ignoring boundary solutions (where the current income constraint (3) bltes so that savings are forced to equal zero), maximization of (1) subject to (2) and (3) leads to unconstrained or notional demand functions for current and future consumption:

$$
\left.\mathrm{c}_{1}\left(\mathrm{p}_{2}, \mathrm{Y}\right) \text { and } \mathrm{c}_{2} \underline{\mathrm{p}}_{2}, \underset{+}{\mathrm{y}}\right)
$$

where the signs of the partial derivatives of the functions in (4) are as indicated. As is well known, the effect on current consumption of a change in the price of future output (i.e., the effect on savings of a change in the interest rate) is indeterminate in general, since the income and substitution effects of such a change work in opposite directions. In the diagrams below we assume for convenience that the substitution effect dominates, so that $\partial c_{1} / \partial p_{2}$ is always positive, but this assumption is not crucial.

Turning next to firms, we assume that their behaviour can be viewed as the outcome of the actions of a representative firm which maximizes the discounted sum of current and future profits: ${ }^{4}$

$$
\pi=\pi_{1}+\beta \pi_{2}
$$

When the firm faces no constraints, it chooses current and future employment levels, $e_{1}$ and $e_{2}$, as well as $I$, the quantity of current output which it holds over as investment to augment the productivity of labour in the future: 


$$
\pi_{1}=F\left(e_{1}\right)-I-w_{1} e_{1}
$$

$$
\pi_{2}=\mathrm{p}_{2} \mathrm{H}\left(\mathrm{e}_{2}, \mathrm{I}\right)-\mathrm{w}_{2} \mathrm{e}_{2}
$$

where $F\left(e_{1}\right)$ is current output and $H\left(e_{2}, I\right)$ is output next period. 5 We assume that production is subject to diminishing returns to each factor in both periods: $\mathrm{F}_{\mathrm{ee}}, \mathrm{H}_{\mathrm{ee}} \mathrm{H}_{\mathrm{II}}<\mathrm{O}$; that labour and investment are complementary in the production of future output: $\mathrm{H}_{\mathrm{eI}}>\mathrm{O}$; and that the production function for future output is strictly concave: $\mathrm{H}_{e e} \mathrm{H}_{I I}-\mathrm{H}_{\mathrm{eI}}^{2}>\mathrm{O}$ (i.e., that labour and investment are subject to diminishing returns to scale). Under these assumptions, unconstrained profit maximization leads to notional employment and investment demand functions, which also imply notional supply functions for both current and future output: 6

$$
e_{1}\left(w_{1}\right), \begin{gathered}
I\left(p_{2}, w_{2}\right) \\
+
\end{gathered}, \quad \text { and } \quad e_{2}\left(p_{2}, w_{2}\right)
$$

implying:

$$
\mathrm{y}_{1}\left(\mathrm{w}_{1}, \mathrm{p}_{2}, \mathrm{w}_{2}\right) \text { and } \mathrm{y}_{2}\left(\mathrm{p}_{2}, \mathrm{w}_{2}\right)
$$

We note that, when firms face no quantity constraints, current employment demand depends only on the current real wage: a change in expected future wages or prices changes the amount of current output held over 
as investment and so changes current sales, but it does not affect current employment and output decisions. Similarly next period's employment and output decisions are independent of the current real wage.

The third and final agent in the economy is the government, which, in addition to taxing firms' profits, can make direct transfer payments to households, increasing their initial endowments $\bar{m}$, or can make direct purchases of goods in both present and future periods, $g_{1}$ and $g_{2}$

Having made these assumptions about the individual agents in the economy, we can now characterize a full Walrasian equilibrium as a triple $\left(w_{1}^{*}, p_{2}^{*}, w_{2}^{*}\right)$ which simultaneously satisfies the notional current and future goods market equilibrium loci (GMEL) and the notional current and future labour market equilibrium 1oci (LMEL):

$$
\begin{aligned}
& \operatorname{GMEL}_{1}: \quad c_{1}\left(p_{2}, Y\right)+g_{1}=y_{1}\left(w_{1}, p_{2}, w_{2}\right) \\
& \text { GMEL }_{2}: \quad c_{2}\left(p_{2}, Y\right)+g_{2}=y_{2}\left(p_{2}, w_{2}\right) \\
& \text { LMEL }_{1}: \quad L=e_{1}\left(w_{1}\right) \\
& \text { LMEL }_{2}: \quad L=e_{2}\left(p_{2}, w_{2}\right)
\end{aligned}
$$


By Walras' Law the four equations are mutually dependent and so we may omit any one from consideration. For the present, we choose to drop the GMEL ${ }_{2}$, which leaves us with three equations in three unknowns. However, in order to permit a two-dimensional representation, we focus on only two variables, $w_{1}$ and $p_{2}$. In the remainder of this paper, therefore, we assume that $w_{2}$ ' the wage rate currently expected to prevail next period, is parametrically fixed (and it is convenient, though quite inessential, to assume in most of the paper that it equals the "full" Walrasian equilibrium value, $\mathbf{w}_{2}^{*}$ ), but the analysis would not be substantially affected if we assumed instead that real-wage expectations were unit elastic (i.e., $w_{2} / p_{2}=w_{1}$ ).

For any given future wage, we can illustrate these loci in $\left(w_{1}, p_{2}\right)$ space, as in Figure 1. The LMEL ${ }_{1}$ uniquely defines $w_{1}^{*}$, points above this locus representing excess supply of, and points below representing excess demand for labour, while the GMEL ${ }_{1}$ is a downward-sloping locus, points above it corresponding to excess demand for goods and points below to excess supply of goods. (We assume that the fall in supply of current output following a rise in $p_{2}$ is more than sufficient to offset any fall in demand.) Finally, the future LMEL $_{2}$ uniquely defines a value of $\mathrm{p}_{2}$, which equals the equilibrium value, $\mathrm{p}_{2}^{*}$, only if the value of $\mathrm{w}_{2}$ underlying the diagram equals the full equilibrium value, $w_{2}^{*}$. It may be noted that the equilibrium at $A$ is globally stable if $w_{1}$ and $p_{2}$ change according to tâtonnement processes. This may be seen more easily by noting that the GMEL ${ }_{1}$ is 
in effect an IS curve, with points above it representing situations where investment demand exceeds savings, requiring a rise in the interest rate (i.e., a fall in $p_{2}$ ) to restore equilibrium and conversely for points below the locus.

When $\mathrm{w}_{1}$ and $\mathrm{p}_{2}$ are rigid, however, the division of the space into disequilibrium regions cannot be the same as in Figure 1, for the by-now well known reason that a disequilibrium in one market will affect decisions in the other market, so affecting the location of the equilibrium loci at all points other than the full Walrasian equilibrium point A. In the remainder of this section we show how the regions are affected when disequilibrium is allowed, on the crucial assumption (to be relaxed in the next section) that all agents expect a Walrasian equilibrium to prevail in the next period. We also assume for simplicity that the same expectations of future wage and price levels are held by all agents and that expectations of future wages are completely inelastic at the Walrasian level $\mathrm{w}_{2}^{*}$.

Consider first the goods market equilibrium locus under conditions of excess supply of labour: firms face no constraints but households are unable to sell the full amount, L, of their endowment of labour services in the current period. Hence the GMEL ${ }_{1}$ becomes: 7

$$
\operatorname{GMEL}_{1}(E S L, w): \quad c_{1}\left(p_{2}, \bar{y}\right)+g_{1}=\dot{y}_{1}\left(w_{1}, p_{2}, \stackrel{*}{*}{ }_{2}\right)
$$

where 


$$
\overline{\mathbf{y}}=\overline{\mathrm{m}}+\mathrm{w}_{1} e_{1}\left(\mathrm{w}_{1}\right)+\mathrm{w}_{2}^{*} \mathrm{~L}, \quad \mathrm{e}_{1}\left(\mathrm{w}_{1}\right)<\mathrm{L}
$$

Since constrained income, $\bar{Y}$, is less than notional income, $Y$, it follows that households' effective consumption demand is reduced as a result of the unemployment they face, and so a point of notional goods market equilibrium in $\left(w_{1}, p_{2}\right)$ space corresponds to effective excess supply of current output. In passing from notional to effective regions, therefore, the $\mathrm{GMEL}_{1}$ (ESL,W) lies to the right of the notional GMEL ${ }_{1}$ ' as shown in Figure 2. However, the two loci only differ for values of $\mathrm{w}_{1}$ greater than $\mathrm{w}_{1}^{*}$, since $i t$ is only in this range that the employment constraint facing households is binding (i.e., $e_{1}\left(w_{1}\right)<L$ ).

A similar argument applies to the GMEL ${ }_{1}$ when the labour market exhibits excess demand: households are now unconstrained whereas firms' current production is constrained by the labour they can obtain: 8

$$
\operatorname{GMEL}_{1}(E D L, W): \quad c_{1}\left(p_{2}, Y\right)+g_{1}=\tilde{y}_{1}\left(\bar{e}_{1} ; p_{2}, \underset{+}{w_{2}^{*}}\right)
$$

$$
=F\left(\bar{e}_{1}\right)-I\left(p_{2}, w_{2}^{*}\right)
$$

where $\bar{e}_{1}$ is simply $L$ and is less than the notional labour demand $e_{1}\left(w_{1}\right)$. We may note that, under our assumptions, the excess demand for labour does not affect firms' investment plans (assuming, of course, that the constraint does not become so severe that their maximum output level falls below their desired level of investment). Comparing 
with (11), it must follow, since the employment constraint bites, that effective supply is less than notional supply, implying that the constrained GMEL, lies to the left of the notional locus when excess demand for labour prevails (i.e., when $w_{1}$ is less than $w_{1}^{*}$ ).

The LMEL $_{1}$ is affected in a similar manner when the goods market is out of equilibrium. Thus, in a situation of excess supply of goods, households are unconstrained but firms are unable to make their notional level of sales. This forces them to recalculate their employment and investment decisions, with the result that the $\mathrm{LMEL}_{1}$ becomes:

$$
\begin{aligned}
\operatorname{LMEL}_{1}(E S G, w): \quad L & =\hat{e}_{1}\left(\bar{y}_{1} ; w_{1}, p_{2}, w_{2}^{*}\right) \\
& =F^{-1}\left[\bar{y}_{1}+\hat{I}_{-}\left(\bar{y}_{1} ; w_{1}, p_{2}, w_{2}^{*}\right)\right]
\end{aligned}
$$

where:

$$
\bar{y}_{1}=c_{1}\left(p_{2}, y\right)+g_{1}<y_{1}\left(w_{1}, p_{2}, w_{2}^{*}\right)
$$

We may note that, by contrast with (8), current employment demand now depends on much more than just the current real wage: the demand for labour is determined both by what firms are able to sell and by what they decide to store. The latter is itself in turn affected by the sales constraint, by contrast with an employment constraint which, as illustrated in equation (16'), does not affect the relative profitability 
of selling and investing. Comparing equations (12) and (17), since constrained employment demand, $\hat{e}_{1}$, is less than notional employment demand, $e_{1}$, a point of notional labour market equilibrium must correspond to effective excess supply of labour when excess supply of goods prevails; (17) therefore lies below (12) in Figure 2. However, comparing (17') with (16'), since constrained investment demand $\hat{I}$ must be greater than notional investment demand $I$, it follows that these two loci do not coincide and that (17) lies above (16). Allowing investment to be carried out by firms therefore leads to an effective region of excess supply of goods and excess demand for labour, or, in the terminology of Muellbauer and Portes (1978), a region of underconsumption.

Finally, when excess demand for goods prevails and the labour market is in equilibrium, firms are in equilibrium, and though households are rationed in the goods market, the assumption that labour is supplied inelastically ensures that this does not affect their labour supply. The effective labour market equilibrium locus therefore coincides with the notional locus.

These shifts from notional to effective equilibrium loci are summarized in Figure 2 (where the notional loci are shown as dashed and the effective loci as solid lines). Following Malinvaud the four regions are labelled $\mathrm{K}$, for Keynesian unemployment, $\mathrm{C}$, for classical unemployment, $R$, for repressed inflation, and $U$, for underconsumption. It may be remarked that region $K$ corresponds to a low expected price 
of future output, and so to a high interest rate: although this might be thought to contradict the Keynesian notion of a liquidity trap, it is in fact fully consistent with Keynes, as will become clearer after the explicit consideration of expectations, to which we now turn.

\section{CONSTRAINT EXPECTATIONS ANO CONSTRAINED EQUILIBRIA}

So far, except for the change in state variables implied by the explicit consideration of two periods and the neglect of the realbalance effect, the present model is extremely similar to that of Barro-Grossman-Malinvaud. ${ }^{9}$ However, some new features are introduced when we abandon the assumption, made throughout the last section, that all agents expect a Walrasian equilibrium to prevail in the future. Instead, we assume in this section that agents expect to face given constraint levels in one or both markets next period. (For simplicity, we retain the assumption that firms and households have the same expectations about which regime will prevail next period. The analysis may easily be extended to examine the implications of heterogeneous expectations).

The first point to emphasize is that if agents expect to be constrained next period this will affect their current behaviour even if $\mathrm{w}_{1}$ and $\mathrm{p}_{2}$ are flexible; in other words, it will shift the notional equilibrium loci. Admittedly, this is not true of the LMEL, equation (12), since labour supply is fixed and, when firms face no constraints 
in the present period, their current employment decisions are determined only by $\mathrm{w}_{1}$. However, the notional GMEL ${ }_{1}$ will be affected. Consider first the case where agents expect regime $K$ (excess supply of both labour and goods) to prevail next period. Equation (10) therefore becomes:

$$
\begin{aligned}
& \operatorname{GMEL}_{1}(\mathrm{~W}, \mathrm{~K}): \quad \mathrm{c}_{1}\left(\mathrm{p}_{2}, \tilde{\mathrm{Y}}\right)+\mathrm{g}_{1}=\hat{\mathrm{y}}_{1}\left(\overline{\mathrm{y}}_{2} ; \mathrm{w}_{1}, \mathrm{w}_{2}^{*}\right) \\
& =F\left[e_{1}\left(w_{1}\right)\right]-\hat{I}\left(\vec{y}_{2} ; \quad w_{+}^{*}\right)
\end{aligned}
$$

where:

$$
\begin{aligned}
& \tilde{\mathrm{Y}}=\overline{\mathrm{m}}+\mathrm{w}_{1} \mathrm{~L}+\mathrm{w}_{2}^{*} \overline{\mathrm{L}}_{2} \quad\left(\overline{\mathrm{L}}_{2}<\mathrm{L}\right) \\
& \overline{\mathrm{y}}_{2}<\mathrm{y}_{2}\left(\mathrm{p}_{2}, \mathrm{w}_{2}^{*}\right)
\end{aligned}
$$

Relative to equation (10), (19) implies an expansion of the region of notional excess supply of goods on two counts: both because households, whose lifetime income is now lower, have a lower consumption demand, and because firms, expecting to face a sales constraint in the future, have a lower investment demand, and so would like to increase their current sales. These two effects are illustrated in Figure 3. The expectation of unemployment by households shifts the notional GMEL ${ }_{1}$ to the right at all points, from the line $(W, W)$ to $\left(W, \bar{L}_{2}\right)$. The expectation of a 
sales constraint also shifts the locus to the right (since a reduction in $\vec{y}_{2}$ raises $\hat{y}_{1}$, and so increases the region of current excess supply of goods). However it does not shift it throughout its length, since a given value of the expected sales constraint $\bar{y}_{2}$ is only binding when it satisfies (21). The shift therefore takes place only for values of $p_{2}$ above $p_{2}^{\circ}$, where $p_{2}^{0}$ (which must be less than $p_{2}^{*}$ ) is the value of $p_{2}$ which satisfies (2l) with equality and is therefore a function of $w_{2}^{*}$ and $\vec{y}_{2}$. The resulting locus is shown by the line denoted $(W, K)$ in Figure 3 .

The effects of other constraint expectations on the notional GMEL $_{1}$ may be illustrated in a similar fashion. Consider, for example, the effect of an expectation of Classical unemployment. The notional GMEL $_{1}$ now becomes: 10

$$
\operatorname{GMEL}_{1}(w, C): \quad \hat{c}_{1}\left(\bar{c}_{2} ; p_{2}, \tilde{Y}\right)+g_{1}=y_{1}\left(w_{1}, p_{2}, w_{2}^{*}\right)
$$

where

$$
\bar{c}_{2}<c_{2}\left(p_{2}, \tilde{Y}\right)
$$

The location of (22) in Figure 3 is easily determined. Assuming that the level of the expected employment constraint $\overline{\mathrm{L}}_{2}$ is the same as in (19), this constraint alone shifts the notional locus as before from $(W, W)$ to $\left(W, \bar{I}_{2}\right)$. The expected consumption constraint $\bar{c}_{2}$ then has the additional effect of shifting the locus to the left, since such a 
constraint raises current demand (because households, expecting to be unable to purchase all the goods they wish in the future, have a reduced incentive to save) and so the region of current excess supply contracts. However, as with (21), this constraint is only effective for those values of $w_{1}$ and $p_{2}$ which satisfy (23). It is easily seen that this inequality defines a region to the left of an upward-sloping locus in Figure 3, which locus must itself lie to the right of A, and so the notional GMEL ${ }_{1}$ when Classical unemployment is expected pivots to the left around point $D$, the intersection of this locus and the $\left(W, \overline{\mathrm{L}}_{2}\right)$ locus.

Finally, since our main concern is to locate the effective equilibrium loci in the diagram, we note that the two effective loci corresponding to (19) and (22) differ from these only in replacing the current notional labour supply I by the corresponding effective supply, $e_{1}\left(w_{1}\right)$; i.e., in replacing $\tilde{\mathrm{Y}}$ by $\overline{\overline{\mathrm{Y}}}$ where:

$$
\overline{\overline{\mathrm{Y}}}=\overline{\mathrm{m}}+\mathrm{w}_{1} e_{1}\left(w_{1}\right)+w_{2}^{*} \overline{\mathrm{L}}_{2}
$$

Hence, moving from notional to effective loci implies (since the current employment constraint is binding only for values of $w_{1}$ above $w_{1}^{*}$ ) that the two loci pivot to the right around their points of intersection with the notional $L_{M E L}{ }_{1}$ i.e., points $A^{\prime}$ and $A^{\prime \prime}$, as shown in Figure 4. Moreover, for the same reasons just given which require the notional GMEL ${ }_{1}$ when Classical unemployment is expected to lie to 
the left of the corresponding locus when Keynesian unemployment is expected, so the locus marked $(E S L, C)$ in Figure 4 must lie wholly to the left of that marked (ESL,K).

This analysis has three important implications. Firstly, even when $w_{1}$ and $p_{2}$ are flexible, there is a continuum of possible "Walrasian" equilibria lying along the notional $\mathrm{LMEL}_{1}$ (including, for example, all points on the segment $A A^{\prime \prime)}$, each one corresponding to a given configuration of constraint expectations. Secondly, when $w_{I}$ and $p_{2}$ are sticky, there is a large region of $\left(w_{1}, p_{2}\right)$ space (including the whole of the area between the two solid lines in Figure 4) which is compatible with either regime $c$ or $K$ prevailing today, the only difference being the state of constraint expectations. 11 Thirdly, constraint expectations tend to be self-fulfilling, in the sense that regime $\mathrm{K}$ is more likely than regime $\mathrm{C}$ to prevail today if it is expected to prevail tomorrow, and conversely.

A similar analysis may be carried out for the effects of other constraint expectations on all four effective equilibrium loci, and broadly similar conclusions follow. However, two qualifications to this statement must be noted. In the first place, the LMEL ${ }_{1}$ under conditions of excess demand for goods turns out to be completely independent of the state of expectations about future constraints, just as we found in the last section that with Walrasian expectations it coincides with the notional $\mathrm{LMEL}_{1}$. The reasons for this are simple: the assumption of an inelastic labour supply ensures that households' expectations do not affect their current labour supply; while the assumptions that the labour market is currently in equilibrium 
and that firms can sell all they currently wish to produce mean that firms' demand for labour depends only on the current wage rate and is independent of whether or not they expect to be constrained in the future. A second qualification is that the complementarity assumed to exist between employment and investment in the second period production function $H($.$) yields some exceptions to the rule that expectations tend$ to be self-fulfilling in the sense defined above. To illustrate this, consider the effective GMEL ${ }_{1}$ when excess demand for labour prevails. When all agents expect to be unconstrained in the future, this is given by equation (16) above. Now suppose instead that they expect regime $R$ to prevail in the future. This yields an alternative locus:

$$
\begin{aligned}
\mathrm{GMEL}_{1}(\mathrm{EDL} ; \mathrm{R}): \quad \hat{\mathrm{c}}_{1}\left(\overline{\mathrm{c}}_{2} ; \mathrm{p}_{2}, \mathrm{Y}\right)+\mathrm{g}_{1} & =\tilde{\tilde{\mathrm{y}}}_{1} \underset{+}{\left(\overline{\mathrm{e}}_{1}, \overline{\mathrm{e}}_{2} ; \mathrm{p}_{2}\right)} \\
& =\mathrm{F}\left(\overline{\mathrm{e}}_{1}\right)-\underset{+}{\tilde{\mathrm{I}}\left(\overline{\mathrm{e}}_{2} ; \mathrm{p}_{2}\right)}+
\end{aligned}
$$

where

$$
\bar{e}_{1}<e_{1}\left(w_{1}\right) \text { and } \bar{e}_{2}<e_{2}\left(p_{2}, w_{2}^{*}\right)
$$

Since consumers expect to be constrained in the goods market in the future, this reduces their incentive to save, and so encourages them to spend more in the present, thus increasing the likelihood that excess demand for goods will prevail today. However, the fact that firms expect to be unable to hire as much labour as they will wish in the future leads them, because of the complementarity between labour and 
investment, to reduce rather than increase their current investment demand. Since their current output is unaffected, this tends to make it more likely that excess supply of rather than excess demand for goods will prevail today. In this case, therefore, the expectation that regime $R$ will prevail tomorrow leads to two effects, one of which makes it more likely but the other of which makes it less likely that regime $R$ will prevail in the present, and there is no presumption in general as to which of these effects will dominate. (Clearly, however, unless the values of $\bar{e}_{2}$ and $\bar{y}_{2}$ are such that $\tilde{I}$ in (25') is considerably less than $\hat{I}$ in (19'), equation (25) must lie to the left of (19)).

Subject to these qualifications, the location of the equilibrium loci under different assumptions about agents' constraint expectations tends to confirm the general points made above: the prevalence of a given regime today depends on the expectations held about which regimes will prevail tomorrow, and in most cases these expectations are of a self-fulfilling kind in the sense already discussed. It is clear that to the extent that the government can influence these expectations, then it possesses an important instrument capable of influencing to a considerable degree the current state of the economy.

\section{RATIONAL CONSTRAINT EXPECTATIONS}

In the last section we examined the effect of arbitrary parametric constraint expectations on the location of the effective equilibrium loci 
in $\left(\mathrm{w}_{1}, \mathrm{p}_{2}\right)$ space. In this section we explore an alternative approach which avoids this arbitrariness of expectations by postulating that households and firms have full information concerning each others' intended future actions. Thus, for example, the labour supply constraint which households expect to face in the next period equals the employment level which firms currently intend to demand in that period. By analogy with the widely studied phenomenon of rational expectations of prices, we label this hypothesis one of rational constraint expectations.

One immediate consequence of the assumption of rational constraint expectations is that the set of regimes which can be expected to prevail next period is restricted. Consider first regime U: if, at a given $\left(w_{1}, p_{2}\right)$ combination, firms are pursuing a production and sales plan which implies that regime $U$ will prevail next period, they must be acting irrationally. For, if they are to be rationed in both labour and goods markets next period, they will end that period with unsold inventories, so foregoing an opportunity to increase their profits. Hence with rational constraint expectations neither households nor firms can expect regime $U$ to prevail next period. A similar argument applies to regime $C$ : households cannot rationally expect to be constrained in both markets next period, and so with rational constraint expectations both households and firms will adjust their plans to ensure that they do not imply such a double rationing in the future. of course, these conclusions are a consequence of the assumption that the world ends at the end of the second period. Nevertheless, while 
allowing for more than one future period would avoid the stark conclusion that (ignoring boundary cases) only regimes $\mathrm{K}$ and $\mathrm{R}$ can be rationally expected, there remains a presumption even in a multi-period model that these regimes are more likely to be expected than $C$ or $U$, since under each of the latter regimes one group of agents is involuntarily building up stocks (of savings or inventories), which is only consistent with rationality if one of the two constraints which these agents face in such a regime is expected to be relaxed in a subsequent period.

Having established which regimes can be rationally expected to prevail next period, we now wish to locate in $\left(w_{1}, p_{2}\right)$ space the regions which are consistent with different disequilibrium regimes when constraint expectations are rational. As in previous sections this requires us to locate in $\left(w_{1}, p_{2}\right)$ space various equilibrium loci, and we illustrate this construction for the case of the current GMEL, assuming that excess supply of labour prevails today and that Keynesian unemployment is rationally expected to prevail tomorrow. This locus is given by solving the following set of four equations in five variables $\left(w_{1}, p_{2}\right.$, $\overline{\mathrm{L}}_{1}, \overline{\mathrm{L}}_{2}$ and $\overline{\mathrm{y}}_{2}$ ) for a single equation in $\mathrm{w}_{1}$ and $\mathrm{p}_{2}$ only:

$$
\operatorname{GMEL}_{1}(\mathrm{ESL}, \mathrm{K} ; \mathrm{RCE}): \quad c_{1}\left[\mathrm{p}_{2} ; \overline{\mathrm{m}}^{-\mathrm{w}_{1}} \overline{\mathrm{L}}_{1}+\mathrm{w}_{2}^{*} \overline{\mathrm{L}}_{2}\right]+\mathrm{g}_{1}=\hat{\mathrm{y}}_{1}\left(\overline{\mathrm{y}}_{2} ; \mathrm{w}_{1}, \mathrm{w}_{2}^{*}\right)
$$

$$
\begin{aligned}
& \overline{\mathrm{L}}_{1}=\mathrm{e}_{1}\left(\mathrm{w}_{1}\right) \\
& \overline{\mathrm{L}}_{2}=\hat{\mathrm{e}}_{2}\left(\overline{\mathrm{y}}_{2} ; \mathrm{w}_{2}^{*}\right)
\end{aligned}
$$


(30)

$$
\overline{\mathrm{y}}_{2}=\mathrm{c}_{2}\left[\mathrm{p}_{2} ; \overline{\mathrm{m}}+\mathrm{w}_{1} \overline{\mathrm{L}}_{1}+\mathrm{w}_{2}^{*} \overline{\mathrm{L}}_{2}\right]+\mathrm{g}_{2}
$$

The construction of the desired equilibrium locus proceeds by substituting from (28) and (29) into (27) and (30), locating these two equations in $\left(w_{1}, p_{2}\right)$ space for different values of $\bar{y}_{2}$, and then tracing the locus of their intersection points as $\bar{y}_{2}$ varies. This is illustrated in Figure 5. The line $\alpha \alpha$ is the Walrasian locus, equation (10), which passes through the full walrasian equilibrium point A. Even if firms do not expect to be sales-constrained next period, rational households will realise that they will face an employment constraint next period if $e_{2}\left(\mathrm{p}_{2},{ }^{*}{ }_{2}\right)$ is less than $L$, i.e., if $\mathrm{p}_{2}$ is less than $\mathrm{p}_{2}^{*}$. Hence, amending (10) to:

$$
c_{1}\left[p_{2} ; \bar{m}+w_{1} L+w_{2}^{*} e_{2}\left(p_{2}, w_{2}^{*}\right)\right]+g_{1}=y_{1}\left(w_{1}, p_{2}, \stackrel{*}{*}\right)
$$

causes it to pivot around point A to give the locus BA. Next, for a given expected sales constraint, $\bar{y}_{2}$, this locus must shift to the right, except at points to the left of $D$, where $p_{2}$ is less than $\mathrm{p}_{2}^{\circ}$ (the solution, as before, of $\overline{\mathrm{y}}_{2}=\mathrm{y}_{2}\left(\mathrm{p}_{2}, \mathrm{w}_{2}^{*}\right)$ ) and so the expected sales constraint is not binding. This yields the locus DA', which is identical to (19) except that the knowledge by households of the dependence of their expected employment constraint on the firms' expected sales constraint is allowed for by substituting for $\overline{\mathrm{L}}_{2}$ from (29). The locus BDA' is therefore the notional GMEL ${ }_{1}$ 
conditional on a sales constraint of $\bar{y}_{2}$ being expected by both firms and households. The corresponding effective GMEL $L_{1}$ is therefore obtained in the usual way by substituting for $\overline{\mathrm{L}}_{1}$ from (28), which causes the locus to pivot around $A^{\prime}$ to give $Y A^{\prime}$, the equation of which is:

$$
\operatorname{GMEL}_{1}\left(\mathrm{ESL}, \mathrm{K} ; \overline{\mathrm{y}}_{2}\right): \quad c_{1}\left[\mathrm{p}_{2} ; \overline{\mathrm{m}}^{\mathrm{w}} \mathrm{w}_{1} \mathrm{e}_{1}\left(\mathrm{w}_{1}\right)+\mathrm{w}_{2}{ }_{2} \hat{\mathrm{e}}_{2}\left(\overline{\mathrm{y}}_{2} ; \mathrm{w}_{2}^{*}\right)\right]+\mathrm{g}_{1}=\hat{\mathrm{y}}_{1}\left(\overline{\mathrm{y}}_{2} ; \mathrm{w}_{1}, \mathrm{w}_{2}^{*}\right)
$$

The next step in deriving the rational-constraint-expectations locus is to locate (30) in the diagram, after substituting from (28) and (29), for given values of $\bar{y}_{2}$. We note first that this locus is upward-sloping if and only if the current elasticity of demand for labour is less than unity (i.e., $\left.\left(w_{1} / e_{1}\right) \partial e_{1} / \partial w_{1}<1\right)$. Making this assumption for diagrammatic convenience, we note also that the locus must pass through $A$ if the expected sales constraint just equals the notional Walrasian supply next period (i.e., if $\bar{y}_{2}=y_{2}\left(w_{1}^{*}, p_{2}^{*}, w_{2}^{*}\right)$ ), and that reductions in $\bar{y}_{2}$ move it progressively to the right. Moreover it may be shown that (provided $\partial c_{1} / \partial p_{2}$ is positive but not too large) a given reduction in $\bar{y}_{2}$ will move (30) to the right by less than it moves (32). Hence corresponding to the locus $\gamma^{\prime}$ ' (equation 32$)$ ) is a locus such as $\delta \delta$ (equation (30)), with both loci conditional on the same value of $\bar{y}_{2}$. The intersection of these two loci at $\mathrm{E}$ therefore represents a point on the effective GMEL $_{1}$ under rational constraint expectations. 
By varying the expected sales constraint $\bar{y}_{2}$ continuously, the desired locus may be traced out, as shown by the heavy line AF. In a similar manner the other effective equilibrium loci under rational constraint expectations may be derived. Without presenting the details of this construction, it is clear that rational constraint expectations do not eliminate the possibility that Keynesian unemployment will prevail today. On the contrary, by working through a similar derivation in order to locate in the diagram the effective $\operatorname{LMEL}_{1}\left(E^{S}, \mathrm{~K}\right)$ under rational constraint expectations, it may be seen that the region in $\left(w_{1}, p_{2}\right)$ space consistent with Keynesian unemployment today is greater when the same state is rationally expected to prevail tomorrow than when Walrasian equilibrium is expected. At the same time, of course, there are some points (such as $\delta$ and $A^{\prime}$ ) which are consistent with Keynesian unemployment today when expectations of future demand constraints are arbitrarily pessimistic, but not when they are rational. Nevertheless, relative at least to the situation where Walrasian equilibrium is expected tomorrow, rational constraint expectations necessarily increase the likelihood that regime $k$, and also regime $R$, will prevail in the current period, for any given $\left(w_{1}, p_{2}\right)$ combination. 12

Having outlined some of the consequences of rational constraint expectations for the location of current disequilibrium regions, we turn in the next section to a brief consideration of their implications for the comparative static responses of the model to exogenous shocks. 


\section{COMPARATIVE STATICS: MULTIPLIERS AND SHIFTS BETWEEN REGIMES}

As is now well known, an analysis of the effects of changes in exogenous variables in a model of temporary equilibrium with rationing must take account of both their effects on the endogenous variables within each region and their effects on the location of the regions themselves.

Considering the latter first, Figures 6 and 7 illustrate the effects of changes in current government expenditure and the state of technology (or, equivalently, the level of profitability), on the location of the four disequilibrium regions assuming Walrasian expectations. An increase in $g_{1}$ shifts the walrasian equilibrium from A to $B$ in Figure 6, implying that, if the economy is initially in Walrasian equilibrium, a cut in government spending will give rise to Keynesian unemployment while a rise in government spending will induce excess demand for goods (without immediately disturbing labour-market equilibrium). Similarly, Figure 7 shows the effects of supply-side shocks on the diagram. An exogenous improvement in profitability (due, for example, to technological progress) affects the loci as shown, assuming (plausibly) that it raises the demand for labour at a given real wage. Hence point A, which represents initial Walrasian equilibrium, moves into a state of Keynesian unemployment, requiring (paradoxically) a rise in the real wage if Walrasian equilibrium is to be restored. Conversely, an exogenous decline in profitability (due, for example, to an increase in the price of an imported input) converts 
an initial state of Walrasian equilibrium into one of classical unemployment, so requiring the classical remedy of a real wage cut.

These effects of changes in current exogenous variables are virtually identical to those which hold in the Barro-Grossman-Malinvaud model. One additional feature of our two-period model is that it permits an examination of the effects of exogenous changes in expectations, both of future constraint levels and of future wages and prices. The effects of changes in the former have already been considered in section 3. As for an increase in $w_{2}$, the expected future wage rate, it has an ambiguous effect on the diagram: on the one hand, it has a substitution effect on production, reducing firms' desired employment next period and so (because of the complementarity in the production function $H($.$) ) reducing current investment demand and$ therefore raising the current supply of output. On the other hand, a rise in $w_{2}$ increases households' lifetime income, so raising their current demand for output. To the extent that this income effect dominates, then an increase in $w_{2}$ has exactly the same effect on the diagram as an increase in $g_{1}$ in Figure 6 , implying that an expected future wage cut will shift the economy from walrasian equilibrium into Keynesian unemployment in the current period.

These relationships between changes in exogenous variables and shifts in the equilibrium loci continue to hold whatever assumptions are made about constraint expectations. In addition, rational 
constraint expectations permit a further role for government policy through the "announcement effects" of a perfectly foreseen change in future government spending. Thus, an increase in $g_{2}$ relaxes the expected future sales constraint on firms, which both raises their current investment demand and (by raising their future labour demand) relaxes the expected future labour-supply constraint facing households. On both counts, the region of excess demand for current output is enlarged, and so with rational constraint expectations a perfectly anticipated increase in $g_{2}$ has exactly the same effect on the diagram as an increase in $g_{1}$ has in Figure 6. Similarly, an anticipated increase in future profitability enlarges the region of current excess supply of goods, and so has effects similar to those of an increase in current profitability in Figure 7.

Turning next to the comparative static properties of the model within different regions, a great many results could be presented, but many of these are familiar from previous studies of the Barro-GrossmanMalinvaud model, and it. would be tedious to present them in detail. However, one issue which is of considerable interest is the effect of rational constraint expectations on the magnitudes of the comparative statics derivatives, and especially of the Keynesian employment multiplier. To examine this, consider first the multiplier when Keynesian unemployment prevails in the current period, but agents make no allowance for future constraints (i.e., they assume that Walrasian equilibrium will prevail next period). Current employment and sales are therefore jointly 
determined by the two equations:

$$
\begin{aligned}
& \overline{\mathrm{L}}_{1}=\hat{\mathrm{e}}_{1}\left(\overline{\mathrm{y}}_{1} ; \mathrm{w}_{1}, \mathrm{p}_{2}, \mathrm{w}_{2}\right) \\
& \overline{\mathrm{y}}_{1}=\mathrm{c}_{1}\left(\mathrm{p}_{2} ; \overline{\mathrm{m}}+\mathrm{w}_{1} \overline{\mathrm{L}}_{1}+\mathrm{w}_{2} \mathrm{~L}\right)+\mathrm{g}_{1}
\end{aligned}
$$

This implies a simple one-period multiplier, very similar to the usual Keynesian expression (the only difference arises from the fact that in our model the marginal propensities to consume out of wages and profits are different, by assumption):

$$
\frac{\partial \overline{\mathrm{L}}_{1}}{\partial \mathrm{g}_{1}}=\left[1-\mathrm{w}_{1} \frac{\partial \hat{\mathrm{e}}_{1}}{\partial \overline{\mathrm{y}}_{1}} \frac{\partial \mathrm{c}_{1}}{\partial \mathrm{y}}\right]^{-1} \frac{\partial \hat{\mathrm{e}}_{1}}{\partial \overline{\mathrm{y}}_{1}}
$$

However, if regime $\mathrm{K}$ both prevails today and is rationally expected to prevail tomorrow, then, since all agents take into account the effect of current events on future behaviour, (33) and (34) must be replaced by the following set of four simultaneous equations:

$$
\begin{aligned}
& \overline{\mathrm{L}}_{1}=\hat{\hat{e}}_{1}\left(\overline{\mathrm{y}}_{1} ; \overline{\mathrm{y}}_{2} ; \mathrm{w}_{1} ; \mathrm{w}_{2}\right) \\
& \overline{\mathrm{y}}_{1}=c_{1}\left(\mathrm{p}_{2} ; \overline{\mathrm{m}}+\mathrm{w}_{1} \overline{\mathrm{L}}_{1}+\mathrm{w}_{2} \overline{\mathrm{L}}_{2}\right)+\mathrm{g}_{1} \\
& \overline{\mathrm{y}}_{2}=c_{2}\left(\mathrm{p}_{2} ; \overline{\mathrm{m}}+\mathrm{w}_{1} \overline{\mathrm{L}}_{1}+\mathrm{w}_{2} \overline{\mathrm{L}}_{2}\right)+\mathrm{g}_{2}
\end{aligned}
$$




$$
\overline{\mathrm{L}}_{2}=\hat{\hat{\mathrm{e}}}_{2}\left(\overline{\mathrm{y}}_{1}, \overline{\mathrm{y}}_{2} ; \mathrm{w}_{1}, \mathrm{w}_{2}\right)
$$

Routine calculations show that under these circumstances the multiplier is :

$$
\frac{\partial \bar{L}_{1}}{\partial g_{1}}=\left[1-\frac{w_{1} A}{1-w_{2} B}\right]^{-1} \frac{\partial \hat{\hat{e}}_{1}}{\partial \bar{y}_{1}}+\frac{w_{2} A}{1-w_{2} B} \frac{\partial \hat{\hat{e}}_{2}}{\partial \bar{y}_{1}}
$$

where:

$$
\begin{aligned}
A & =\frac{\partial \hat{\hat{e}}_{1}}{\partial \bar{y}_{1}} \frac{\partial c_{1}}{\partial Y}+\frac{\partial \hat{\mathrm{e}}_{1}}{\partial \bar{y}_{2}} \frac{\partial c_{2}}{\partial Y} \\
B & =\frac{\partial \hat{\hat{e}}_{2}}{\partial \bar{y}_{1}} \frac{\partial c_{1}}{\partial Y}+\frac{\partial \hat{\mathrm{e}}_{2}}{\partial \bar{y}_{2}} \frac{\partial c_{2}}{\partial \bar{Y}}
\end{aligned}
$$

There are three distinct reasons why (40) exceeds (35). Firstly, as shown in the Appendix, $\partial \hat{\hat{e}}_{1} / \partial \bar{y}_{1}$ exceeds $\partial \hat{e}_{1} / \partial \bar{y}_{1}$ (at least locally); i.e., a relaxation of the current sales constraint faced by firms has a greater impact effect on their current demand for labour when they expect to face a similar constraint in the future than when they expect to be unconstrained. This result, which reflects the Le Chatelier principle, does not arise because expectations are rational but solely because they are "Keynesian": hence government policy has a greater expansionary effect when firms are pessimistic about their future sales prospects. Secondly, a relaxation of the current sales constraint also causes firms to revise their future employment plans 
upwards, but with rational constraint expectations households know that this raises their lifetime income and so they increase their consumption in both periods thus having a further impact effect on firms' current demand for labour. Finally, and probably most importantly, with rational constraint expectations the multiplier itself is increased, or rather, it might be more correct to say that there are now not one but many multipliers, operating both within and between periods. Even though the government injection is not repeated next period, the relaxation of a current constraint on one group of agents has an enhanced expansionary effect by relaxing the constraints which the other group expects to face in the future, and so on.

These findings illustrate the important point that the implications of rational expectations for the effectiveness of government policy depend completely on whether or not they are accompanied by sufficient price flexibility to ensure market clearing without rationing. When prices are rigid, rational constraint expectations, at least in the present model, actually enhance the effectiveness of traditional fiscal policy.

\section{DISEQUILIBRIUM REGIMES WITH CURRENT WAGE-PRICE FLEXIBILITY}

So far we have followed both Solow-Stiglitz and Barro-GrossmanMalinvaud in assuming that at least one current price or wage rate is inflexible in the current period. If we relax this assumption and 
assume that $w_{1}$ is perfectly flexible (though $p_{2}$ and $w_{2}$ are still exogenous) then there are two possibilities: $w_{1}$ may move to clear either the current labour market or the current goods market.

If $\mathrm{w}_{1}$ is assumed to move to clear the current labour market, then for a given value of $\mathrm{p}_{2}$ the only possible equilibrium is at the corresponding point on one of the two effective labour market equilibrium loci in Figures 2 to 7 . With this qualification much of the analysis in previous sections continues to be relevant, the only additional feature being that the slope of the effective $\mathrm{LMEL}_{1}$, when excess supply of goods prevails, now becomes a crucial determinant of the efficacy of wage flexibility in ensuring continual full employment. Consider, for example, this locus when agents expect to be unconstrained next period - equation (17) - and totally differentiate it (substituting for $\bar{y}_{1}$ from (18)):

$$
\left[\frac{\partial \hat{e}_{1}}{\partial \bar{y}_{1}} \frac{\partial c_{1}}{\partial y}+\frac{\partial \hat{e}_{1}}{\partial w_{1}}\right] d w_{1}=-\left[\frac{\partial \hat{e}_{1}}{\partial \bar{y}_{1}} \frac{\partial c_{1}}{\partial p_{2}}+\frac{\partial \hat{e}_{1}}{\partial p_{2}}\right] d p_{2}
$$

The coefficient of $\mathrm{dp}_{2}$ will generally be negative, but the coefficient of dw will be positive - implying that this locus, which is the boundary between regions $\mathrm{K}$ and $\mathrm{U}$ in Figure 2, is downward-sloping - if the first or "Keynesian" term in parentheses dominates the second "Classical" term, $\partial \hat{e}_{1} / \partial w_{1}$. If this happens, then even a small displacement of $\mathrm{p}_{2}$, the expected future goods price, below its Walrasian equilibrium level, may require a considerable fall in the current real 
wage, possibly even to zero, if labour market equilibrium is to be restored. This suggests that under the present set of assumptions current wage flexibility may be anything but a painless means of ensuring continual full employment, if expectations of future wage and price levels are inelastic.

But in any case the assumption of the preceding paragraph, that the real wage moves to clear the current labour market, runs counter to a long tradition in macro-economics which argues that goods markets clear rapidly by price adjustment whereas the labour market does not. It would be more consistent with this tradition (which finds expression, of course, in Keynes's General Theory and in the IS-LM model of income determination) to assume that $\mathrm{w}_{1}$, or rather its inverse, the price of current output in terms of "wage-units", adjusts to clear the current goods market rather than the current labour market. With this change in assumptions, the model becomes one with current wage-price flexibility, but in which the given expectations of future wages and prices can give rise to either excess demand for or excess supply of labour in the present period.

It is most convenient to analyse the model under this new assumption by setting up the diagrams in $\left(\mathrm{w}_{2}, \mathrm{p}_{2}\right)$ space. Considering notional equilibrium first, the notional $\mathrm{GMEL}_{1}$, equation (10), may be solved for the value of $\mathrm{w}_{1}$ which clears the current goods market, as a function of parametric wage and price expectations and of the level 
of current government expenditure:

$$
\mathrm{w}_{1}=\phi\left(\underline{p}_{2}, \mathrm{w}_{2} ; \mathrm{g}_{1}\right)
$$

The signs of the partial derivatives of $\phi($.$) imply that an increase in$ either $\mathrm{p}_{2}$ or $\mathrm{w}_{2}$ gives rise to excess demand for current output (so requiring a fall in $w_{1}$ to restore equilibrium). The former effect has already been assumed in Section 2; the latter assumes that the income effect on households of a higher expected future wage rate raises current consumption demand by more than the substitution effect on firms lowers current investment demand. Substituting from (44) into (12) yields the notional $\mathrm{LMEL}_{1}$ in $\left(\mathrm{w}_{2}, \mathrm{p}_{2}\right)$ space:

$$
\operatorname{LMEL}_{1}(W, W): \quad L=e_{1}\left[\phi\left(p_{2} ; w_{2} ; g_{1}\right)\right]
$$

As shown in Figure 8, equation (45) defines a downward-sloping locus in $\left(\mathrm{w}_{2}, \mathrm{p}_{2}\right)$ space, with points above corresponding to excess demand for and points below to excess supply of labour in the current period. The diagram also shows equation (13), the notional future labour market equilibrium locus, which is upward-sloping and intersects (45) at the full Walrasian equilibrium point $\left(\mathrm{w}_{2}^{*}, \mathrm{p}_{2}^{*}\right)$.

Moving from notional to effective equilibria does not affect either locus, as long as we continue to assume that constraint expectations are Walrasian, since the current goods market always clears. 
Of course, at all points off the LMEL ${ }_{1}$ the equilibrium value of $w_{1}$ is determined not by (10) but by either (14) or (16), and this must be taken into account in evaluating the comparative statics properties of the model. Notice that under these assumptions there can be no multiplier, since there is no market on which both buyers and sellers are simultaneously subject to constraints.

Suppose next that agents have arbitrary expectations of future constraints. $^{13}$ If excess supply of labour is expected then current consumption demand is lower than when expectations are Walrasian, and so a rise in the current real wage is required to choke off the incipient excess supply of current output. This causes a fall in the current demand for labour, and so the region of current excess labour supply expands. Formally, (45) must now be replaced by:

$$
\operatorname{LMEL}_{1}(W, E S L): \quad L=e_{1}\left[\begin{array}{cccc}
\tilde{\phi}_{(}\left(\overline{\mathrm{L}}_{2} ;\right. & \mathrm{P}_{2}, & \mathrm{w}_{2} ; & \left.\mathrm{g}_{1}\right) \\
-2 & - & -
\end{array}\right]
$$

where $\tilde{\phi}($.$) gives the solution for w_{1}$ of equation (10) with households' lifetime income equal to $\tilde{Y}$ (equation (20)) rather than $Y$. As in Section 3, therefore, expectations of unemployment exhibit a "bootstraps" property: the region of $\left(w_{2}, p_{2}\right)$ space consistent with unemployment today is larger the more pessimistic the expectation of unemployment tomorrow.

By contrast, if excess demand for labour is expected to prevail tomorrow, the likelihood of current excess supply of rather than 
demand for labour is increased, and so the "bootstraps" phenomenon does not emerge. As in section 3, this arises because of the complementarity between employment and investment next period: if firms expect to face a labour-market constraint their current investment demand falls; to avoid a current excess supply of goods $\mathrm{w}_{1}$ must rise, and so the region of current excess supply of labour expands. Of course, as in Section 3 , this argument must be qualified by the fact that an arbitrary expected employment constraint $\bar{e}_{2}$ is only binding if it is less than the notional future demand for labour:

$$
\bar{e}_{2}<e_{2}\left(p_{2}, w_{2}\right)
$$

When $\bar{e}_{2}$ equals $L$ equation (47) with equality is simply the LMEL 2 ; if firms (irrationally) expect to face an employment constraint less than $L$ then (47) with equality is an upward-sloping locus with the same slope as, but to the left of, the $\mathrm{LMEL}_{2}$. In either case the area within which (47) binds is to the right of this locus, and so arbitrary expectations of excess demand for labour affect the diagram as shown in Figure 9, causing the region of current unemployment to expand rather than contract.

What if constraint expectations are rational? Once again, this does not rule out unemployment or excess demand for labour in the current period. However, under the assumptions of the present section it introduces a new feature: not all $\left(\mathrm{w}_{2}, \mathrm{p}_{2}\right)$ combinations are now 
consistent with a rational-constraint-expectations equilibrium, because at most only two markets in both periods can be out of Walrasian equilibrium. To illustrate this point, consider the possibility of a rational-constraint-expectations equilibrium exhibiting excess supply of labour in both periods. Such an equilibrium must lie in the region to the left of both loci in Figure 8 . But the $\left(w_{2}, p_{2}\right)$ coordinates of an arbitrary point in this region uniquely determine a second-period level of employment (since the latter always equals $e_{2}\left(p_{2}, w_{2}\right)$ in this region); when combined with the requirement that the first-period goods market must clear this in turn determines unique values for $w_{1}$ and $\bar{L}_{1}$, the first-period level of employment. But with rational constraint expectations it is necessary that these values of $\left(w_{1}, p_{2}, w_{2}, \bar{L}_{1}, \bar{L}_{2}\right)$ be such that the second-period goods market is guaranteed to clear. In other words, their values must satisfy the relevant $\mathrm{GMEL}_{2}$ :

(48) $\operatorname{GMEL}_{2}(\mathrm{ESL}, \mathrm{ESL}): \quad \mathrm{c}_{2}\left[\mathrm{p}_{2} ; \overline{\mathrm{m}}+\mathrm{w}_{1} \mathrm{e}_{1}\left(\mathrm{w}_{1}\right)+\mathrm{w}_{2} \mathrm{e}_{2}\left(\mathrm{p}_{2}, \mathrm{w}_{2}\right)\right]+\mathrm{g}_{2}=\mathrm{y}_{2}\left(\mathrm{p}_{2}, \mathrm{w}_{2}\right)$

where the current real wage is such that it clears the current goods market; i.e., $w_{1}$ must satisfy:

(49) $\operatorname{GMEL}_{1}(\mathrm{ESL}, \mathrm{ESL}): \quad c_{1}\left[\mathrm{p}_{2} ; \overline{\mathrm{m}}+\mathrm{w}_{1} \mathrm{e}_{1}\left(\mathrm{w}_{1}\right)+\mathrm{w}_{2} \mathrm{e}_{2}\left(\mathrm{p}_{2}, \mathrm{w}_{2}\right)\right]+\mathrm{g}_{1}=\mathrm{y}_{1}\left(\mathrm{w}_{1}, \mathrm{p}_{2}, \mathrm{w}_{2}\right)$

These two equations define a locus in $\left(w_{2}, p_{2}\right)$ space, whose location may be determined by means of the same geometric techniques that were 
used in Section 4, and which is illustrated by the dashed line in Figure 8.

This construction (which may be repeated for other kinds of equilibria) illustrates the point that only some $\left(\mathrm{w}_{2}, \mathrm{p}_{2}\right)$ combinations are consistent with rational constraint expectations when the current wage rate is flexible and the goods market clears in both periods. But it also shows that even current wage flexibility combined with rational expectations does not eliminate unemployment: any rigidity, even if only in expected future wages and prices (which are generally unobservable, of course), is sufficient to rule out the necessity of full employment prevailing today and hence to provide a role for anticipated changes in government policy.

\section{SUMMARY AND CONCLUSION}

This paper has presented a simple two-period model of temporary equilibrium with rationing which lays considerable stress on agents' expectations of the constraints which they may face in the future. Arbitrary constraint expectations were shown to permit multiple equilibria, with more than one regime in the present period being consistent with a given vector of current and expected future wages and prices. Moreover, such expectations were shown to exhibit a "bootstraps" property, so that, for example, Keynesian unemployment 
is more likely than Classical unemployment to prevail today if it is expected to prevail tomorrow, and vice versa.

It was also shown that Walrasian equilibrium and the impotence of goverment policy are not guaranteed by rational constraint expectations, in the sense of perfect foresight of future constraint levels. On the contrary, such expectations actually increase the probability that Keynesian unemployment will prevail today relative to Walrasian expectations, and they raise the value of the government multiplier. Even when all current prices and wages are flexible, as in section 6 , rational expectations do not guarantee full employment: any rigidity in wages or prices, even if only in the expectations of their future levels - which in any case is highly likely, given the absense of futures markets - is sufficient to generate excess demand for or excess supply of labour in the current period. These results suggest that the critique of the effectiveness of government policy presented by "new Classical macroeconomists", such as Lucas (1973) and Sargent and Wallace (1975), rests primarily on their assumption that wages and prices move instantaneously to clear markets, and not on their use of the rational expectations hypothesis.

One obvious objection to our concept of rational constraint expectations (obvious at least to Robert Barro, whom we thank for pointing it out) is that with so much information available agents should be able to change prices directly to attain the first-best Walrasian equilibrium. We believe, however, that this type of argument 
greatly underestimates the difficulties of concerting individual behaviour in a decentralised economy with highly imperfect information. In any case, we defend rational constraint expectations, not on the grounds that we believe in their descriptive realism, but because they isolate the role of wage-price rigidities (including rigidities in expected future wages and prices) in giving rise to unemployment, intermarket spillovers, and other such Keynesian phenomena.

Finally, we would argue that even though wage-price flexibility may eventually bring the economy to Walrasian equilibrium it is unlikely to do so by a swift or easy route. The facts that shifts in expectations may bring about substantial changes in the wage-price vector required to achieve Walrasian equilibrium, and that (as noted in Section 6) the market whose price is sticky need not be the one which fails to clear, suggest a sort of "dynamic second-best theorem": with limited flexibility of some prices, increasing the flexibility of other prices may reduce rather than increase the ability of the system to return to Walrasian equilibrium. A full consideration of such dynamic problems, as well as an evaluation of the ability of the real-balance effect - excluded by assumption from our model - to ensure the reattainment of equilibrium, are topics to which we hope to return. 
APPENDIX

\section{THE BEHAVIOUR OF THE FIRM}

The behaviour of the firm under different constraint regimes can be derived directly bY solving (6) subject to (7), (8) and appropriate additional constraints, but it is easier and more illuminating to adopt a dual approach, along with the concept of "virtual" prices used by Neary and Roberts (1979).

Consider first the case of no constraints in either period, where we may define the unconstrained profit function as follows (note that it is convenient throughout this Appendix to work with $p_{1}$ explicitly):

$$
\pi\left(p_{1}, w_{1}, p_{2}, w_{2}\right)=\underset{e_{1}, e_{2}, I}{\operatorname{Max}}\left[p_{1}\left\{F\left(e_{1}\right)-I\right\}-w_{1} e_{1}+p_{2} H\left(e_{2}, I\right)-w_{2} e_{2}\right]
$$

By Shephard's Lemma the partial derivatives of this function give the unconstrained employment demand and output supply functions for each period:

(A.2)

$$
\pi_{p_{1}}=y_{1} \quad \pi_{w_{1}}=-e_{1} \quad \pi_{p_{2}}=y_{2} \quad \pi_{w_{2}}=-e_{2}
$$

Suppose now that the firm faces a sales constraint in the current period: $\overline{\mathrm{Y}}<\mathrm{Y}_{1}$. Its behaviour in this case may be deduced from the 
constrained profit function, $\hat{H}\left(\overline{\mathrm{y}}_{1} ; \mathrm{p}_{1}, \mathrm{w}_{1}, \mathrm{p}_{2}, \mathrm{w}_{2}\right)$, and as in Neary and Roberts (op.cit.), the properties of the latter are most easily determined by relating it to the unconstrained profit function evaluated at the virtual price $\bar{p}_{1}$ :

(A.3) $\quad \pi\left(\bar{y}_{1} ; p_{1}, w_{1}, p_{2}, w_{2}\right)=\operatorname{Max}\left[\pi\left(p_{1}, w_{1}, p_{2}, w_{2}\right): \quad y_{1} \leq \bar{y}_{1}\right]$

(A. 4)

$$
=\pi\left(\overline{\mathrm{p}}_{1}, \mathrm{w}_{1}, \mathrm{p}_{2}, \mathrm{w}_{2}\right)+\left(\mathrm{p}_{1}-\overline{\mathrm{p}}_{1}\right) \overline{\mathrm{y}}_{1}
$$

where the virtual price, that price which would induce an unconstrained firm to produce $\bar{y}_{1}$ ! is defined implicitly by:

$$
\bar{y}_{1}=\pi_{p_{1}}\left(\bar{p}_{1}, w_{1}, p_{2}, w_{2}\right)
$$

It is easily seen that the constrained and unconstrained current employment demand functions coincide when the latter is evaluated at the virtual price $\bar{p}_{1}$ :

$$
\hat{e}_{1}=-\hat{\pi}_{w_{1}}=-\pi_{w_{1}}-\left(\pi_{p_{1}}-\vec{y}_{1}\right) \frac{\partial \vec{p}_{1}}{\partial w_{1}}=-\pi_{w_{1}}
$$

Hence the effect of a change in the sales constraint on current employment demand is found to be:

$$
\frac{\partial \hat{e}_{1}}{\partial \bar{y}_{1}}=-\pi_{w_{1} p_{1}} \frac{\partial \bar{p}_{1}}{\partial \bar{y}_{1}}
$$


$(A .8)$

$$
=-\pi_{w_{1} p_{1}} \pi_{p_{1} p_{1}}^{-1}>0
$$

Other properties of the firm's behaviour in the face of the sales constraint may be deduced in a similar manner. For example:

$$
\frac{\partial \hat{\mathrm{e}}_{1}}{\partial \mathrm{w}_{1}}=-\pi_{\mathrm{w}_{1} \mathrm{w}_{1}}-\pi_{\mathrm{w}_{1} \mathrm{p}_{1}} \frac{\partial \overline{\mathrm{p}}_{1}}{\partial \mathrm{w}_{1}}
$$

$(A .10)$

$$
=\frac{\partial e_{1}}{\partial w_{1}}+\pi_{w_{1} p_{1}} \cdot \pi_{p_{1} p_{1}}^{-1} \pi_{p_{1} w_{1}}
$$

Since the second term in $(A .10)$ is positive this yields a Le Chateliertype result: the imposition of a sales constraint reduces (at least locally) the responsiveness of employment demand to a change in wages.

Consider next the case where the firm faces a sales constraint in both periods: $\bar{y}_{1}<y_{1}$ and $\bar{y}_{2}<y_{2}$. We may proceed in an analogous fashion to define a doubly-constrained profit function:

$$
\hat{\hat{\pi}}\left(\bar{y}_{1}, \bar{y}_{2} ; p_{1}, w_{1}, p_{2}, w_{2}\right)=\operatorname{Max}\left[\hat{\pi}\left(\bar{y}_{1} ; p_{1}, w_{1}, p_{2}, w_{2}\right): \quad \hat{y}_{2} \leq \bar{y}_{2}\right]
$$

$$
=\hat{\pi}\left(\bar{y}_{1} ; p_{1}, w_{1} \cdot \bar{p}_{2}, w_{2}\right)+\left(p_{2}-\bar{p}_{2}\right) \bar{y}_{2}
$$

$$
=\pi\left(\bar{p}_{1}, w_{1}, \bar{p}_{2}, w_{2}\right)+\left(p_{1}-\bar{p}_{1}\right) \bar{y}_{1}+\left(p_{2}-\bar{p}_{2}\right) \bar{y}_{2}
$$


The two virtual prices, $\bar{p}_{1}$ and $\bar{p}_{2}$, corresponding to the two constraints $\bar{y}_{1}$ and $\bar{y}_{2}$, are now jointly determined by (A.5) (with $\bar{p}_{2}$ replacing $\mathrm{P}_{2}$ ) and $(\mathrm{A} .14)$ :

$$
\bar{y}_{2}=\pi_{p_{2}}\left(\bar{p}_{1}, w_{1}, \bar{p}_{2}, w_{2}\right)
$$

As before the doubly-constrained and unconstrained labour demand functions coincide when the latter is evaluated at $\bar{p}_{1}$ and $\bar{p}_{2}$ :

$$
\hat{\hat{e}}_{1}=-\hat{\hat{\pi}}_{w_{1}}=-\hat{\pi}_{w_{1}}=-\pi_{w_{1}}
$$

Hence:

$$
\frac{\partial \hat{\hat{e}}_{1}}{\partial \bar{y}_{1}}=-\pi_{w_{1} p_{1}} \frac{\partial \bar{p}_{1}}{\partial \bar{y}_{1}}-\pi_{w_{1} p_{2}} \frac{\partial \bar{p}_{2}}{\partial \bar{y}_{1}}
$$

This may be simplified by recalling that $\pi_{w_{1} p_{2}}$ is zero (i.e. unconstrained current employment demand is independent of the future output price) and by solving $(A .5)$ and $(A .14)$ for $\partial \bar{p}_{1} / \partial \bar{y}_{1}$. This yields:

$$
\frac{\partial \hat{\hat{e}}}{\partial \bar{y}_{1}}=-\pi_{w_{1} p_{1}}\left[\pi_{p_{1} p_{1}}-\pi_{p_{1} p_{2}} \pi_{p_{2} p_{2}}^{-1} \pi_{p_{2} p_{1}}\right]^{-1}
$$

This is clearly greater than (A.8), which proves that (as was asserted 
in Section 5) the presence of an expected future sales constraint increases the responsiveness of current employment demand to a relaxation of the current sales constraint.

It should be clear how these techniques may be used to deduce the behaviour of the firm in the presence of other combinations of constraints. 


\section{FOOTNOTES}

1. The Barro-Grossman-Malinvaud model has been further examined and extended by Hildenbrand and Hildenbrand (1977), Hool (1978), and Muellbauer and Portes (1978); its dynamic behaviour (under tâtonnement-type assumptions) has been studied by Barro and Grossman (1976, Chap. 2), Blad and Kirman (1978), Böhm (1978), Dehez and Gabszewicz (1978) and Honkapohja (1978); and it or similar models have been applied to public finance by Dixit (1976) and to international economics by Dixit (1978) and Neary (1979).

2. For a detailed examination of the causes and consequences of wage and price rigidities, see Stiglitz (1978).

3. Note that the model is a monetary one, but only in a rudimentary way. Wage payments in the first period are made in the form of money, since if they were made in the form of goods the model would always satisfy Say's Law. However the purchasing power of money is fixed in terms of current output, and so the model contains only three relative prices: $\mathrm{w}_{1}, \mathrm{p}_{2}$ and $\mathrm{w}_{2}$.

4. If capital markets were perfect, the discount factor $\beta$ would equal unity (since $\mathrm{p}_{2}$ is a present-value expected price, and so has already been deflated by one plus the discount rate). Allowing $\beta$ to differ from unity is therefore an artificiality attempting to capture the effects of imperfections in the capital market. 
5. If the state of technology is given, the current production function $F($.$) may be viewed as identical to the future production function H($. with a predetermined level of investment: $F\left(e_{1}\right)=H\left(e_{1}, \bar{I}\right)$. We explicitly assume that $H($.$) exhibits diminishing returns to scale (thus ruling out,$ for example, the form $\left.\mathrm{H}\left(\mathrm{e}_{2}, \mathrm{I}\right)=\mathrm{F}\left(\mathrm{e}_{2}\right)+\mathrm{I}\right)$ since otherwise futureperiod production levels would be indeterminate unless firms expected to face a sales constraint next period.

6. The derivation of the firm's behavioural functions is sketched in the Appendix.

7. Henceforward each effective equilibrium locus is specified as contingent on two regimes, indicated in parentheses: the first is the regime which prevails in the current period, and the second that which is expected to prevail next period.

8. As in Neary (1979) we adopt the following notational convention: a bar over a variable (e.g., $\overline{\mathbf{e}}_{1}$ ) indicates that, from the point of view of the agent under consideration, its value is predetermined in the current period; a tilde $\left(e . g ., \tilde{y}_{l}\right)$ indicates a function or parameter arising from behaviour in the face of a labour-market constraint; a circumflex (e.g.. $\hat{y}_{1}$ ) indicates behaviour in the face of a goods-market constraint; and corresponding symbols are used to indicate behaviour in the face of multiple constraints $\left(e . g ., \hat{\hat{y}}_{1}, \tilde{\tilde{e}}_{1}\right.$, etc.) 
9. Figures 1 and 2 are in fact identical to the corresponding diagrams illustrating the regions of notional and effective equilibria in $(w / p, m / p)$ space in the Barro-Grossman-Malinvaud model, provided it is assumed that labour is supplied inelastically and that investment may be carried out by firms. When reinterpreted in this way, Figure 2 may be used to illustrate a point made in Section 1 above: Consider a Barro-Grossman-Malinvaud economy where the real wage is at its Walrasian level but initial nominal money balances are too low to achieve full employment (i.e., the initial equilibrium lies directly to the left of point $A$ in the diagram corresponding to Figure 2). In these circumstances a proportionate reduction in $w$ and $p$ will necessarily restore full employment through the real-balance effect.

10. Because of our assumptions about the form of the household's utility function, the constrained consumption function in (22) is determined by the budget constraint alone, and so takes the particularly simple form: $\hat{\mathbf{c}}_{1}=\tilde{Y}-p_{2} \bar{c}_{2}$. We continue to assume that the effect of an increase in $\mathrm{p}_{2}$ in reducing current supply outweighs its depressing effect on demand; i.e., that a fall in the interest rate raises investment demand by more than it raises the supply of savings.

11. It should be clear that multiple equilibria follow in our one-consumer model from the presence of parametric constraint expectations, by contrast with the model of Hildenbrand and Hildenbrand (1977) where 
multiple equilibria arise from the assumption of general utility functions combined with a disaggregated consumer sector, in a model which is otherwise identical to Malinvaud's.

12. Whether or not rational constraint expectations are consistent with multiple equilibria is still an unresolved question. Guy Laroque has proved, in a model which is formally rather similar to ours, although its interpretation is different, that rationing equilibria are unique in the neighbourhood of the Walrasian equilibrium, which suggests that the multiple equilibria which (as we showed in Section 3) are very likely to arise when constraint expectations are arbitrary, cannot arise when constraint expectations are rational. of course, multiple equilibria are still possible in the sense that a given $\left(w_{1}, p_{2}\right)$ combination may be consistent with a number of different current regimes when constraint expectations are rational, depending on the (unobservable) value of the expected future wage rate $w_{2}$.

13. We assume for simplicity that agents never expect disequilibrium in the future goods market. 


\section{REFERENCES}

Barro, R.J. and H.I. Grossman (1971): "A General Disequilibrium Model of Income and Employment", American Economic Review, Vol. 61, 82-93.

Barro, R.J. and H.I. Grossman (1976): Money, Employment and Inflation, Cambridge: Cambridge University Press.

Benassy, J.P. (1975): "Neo-Keynesian Disequilibrium in a Monetary Economy", Review of Economic Studies, Vol. 42, 503-523.

Blad, M.C., and A.P. Kirman (1978): "The Long-Run Evolution of a Rationed Equilibrium Model", University of Warwick Economic Research Paper, No. 128.

Böhm, V. (1978): "Disequilibrium Dynamics in a Simple Macroeconomic Model", Journal of Economic Theory, Vol. 17, 179-199.

Clower, R.W. (1965): "The Keynesian Counter-Revolution: A Theoretical Appraisal", in F.H. Hahn and F. Brechling (eds.): The Theory of Interest Rates, London: Macmillan.

Dehez, P. and J.J. Gabszewicz (1978): "Savings Behaviour and Disequilibrium Analysis", Colloques Internationaux du C.N.R.S., No:. 259, 197-212; CORE Reprint No. 313.

Dixit, A.K. (1976): "Public Finance in a Keynesian Temporary Equilibrium", Journal of Economic Theory, Vol. 12, 242-58. 
Dixit, A.K. (1978): "The Balance of Trade in a Model of Temporary Equilibrium with Rationing", Review of Economic Studies, Vol. 45, 393-404.

Grandmont, J.M. (1977): "Temporary General Equilibrium Theory", Econometrica, Vol. 45, 535-573.

Hansen, B. (1951): A Study in the Theory of Inflation, London: Allen and Unwin.

Hicks, J.R. (1974): The Crisis in Keynesian Economics, Oxford: Basil Blackwell.

Hildenbrand, K., and W. Hildenbrand (1976): "On Malinvaud's 'Reconsideration of the Theory of Unemployment'", Institute of Business and Economic Research, University of California, Berkeley, Paper No. 244, December.

Honkapohja, S. (1978): "On the Dynamics of Disequilibria in a Macro Model with Flexible Wages and Prices", mimeo, Yrjö Jahnsson Foundation, Heksinki.

Hool, B. (1977): "Monetary and Fiscal Policies in Equilibria with Rationing", mimeo., University of Wisconsin, Madison.

Leijonhufoud, A. (1968): On Keynesian Economics and the Economics of Keynes, New York: Oxford University Press. 
Lucas, R.E. (1973): "Some International Evidence on Output-Inflation Trade-offs"; American Economic Review, Vol. 63, 326-34.

Malinvaud, E. (1977): The Theory of Unemployment Reconsidered, Oxford: Basil Blackwell.

Muellbauer, J., and R. Portes (1978): "Macroeconomic Models with Quantity Rationing", Economic Journal, Vol. 88, 788-821.

Neary, J.P. (1979): "Non-Traded Goods and the Balance of Trade in a Neo-Keynesian Temporary Equilibrium", Quarterly Journal of Economics (forthcoming).

Neary, J.P. and K.W.S. Roberts (1979): "The Theory of Household Behaviour under Rationing", European Economic Review (forthcoming).

Patinkin, D. (1965): Money, Interest and Prices: An Integration of Monetary and Value Theory, Second Edition, New York: Harper and Row.

Sargent, T.J. and N. Wallace (1975): "'Rational' Expectations, the Optimal Monetary Instrument, and the Optimal Money Supply Rule", Journal of Political Economy, Vol. $83,241-54$.

Solow, R.M. and J.E. Stiglitz (1968): "Output, Employment and Wages in the Short Run", Quarterly Journal of Economics, Vol. 82, 537-60.

Stiglitz, J.E. (1978): 'Lectures in Macroeconomics, All Souls' college, Oxford. 


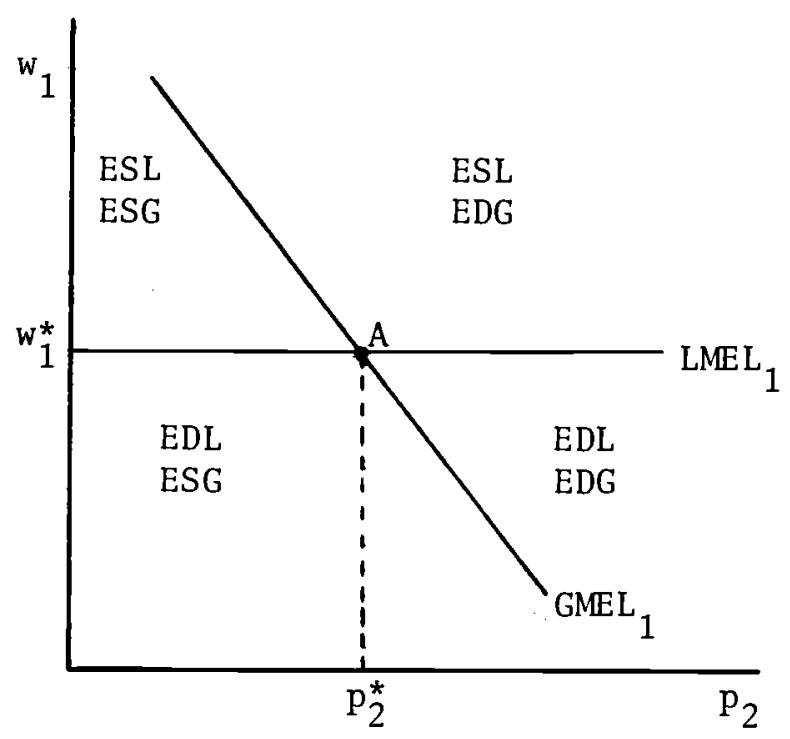

Figure 1

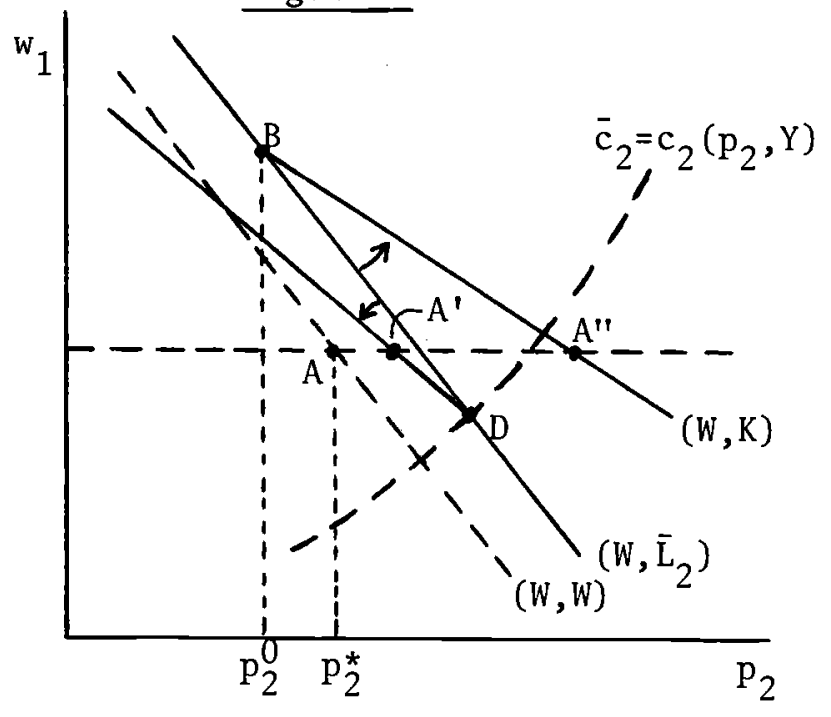

Figure 3
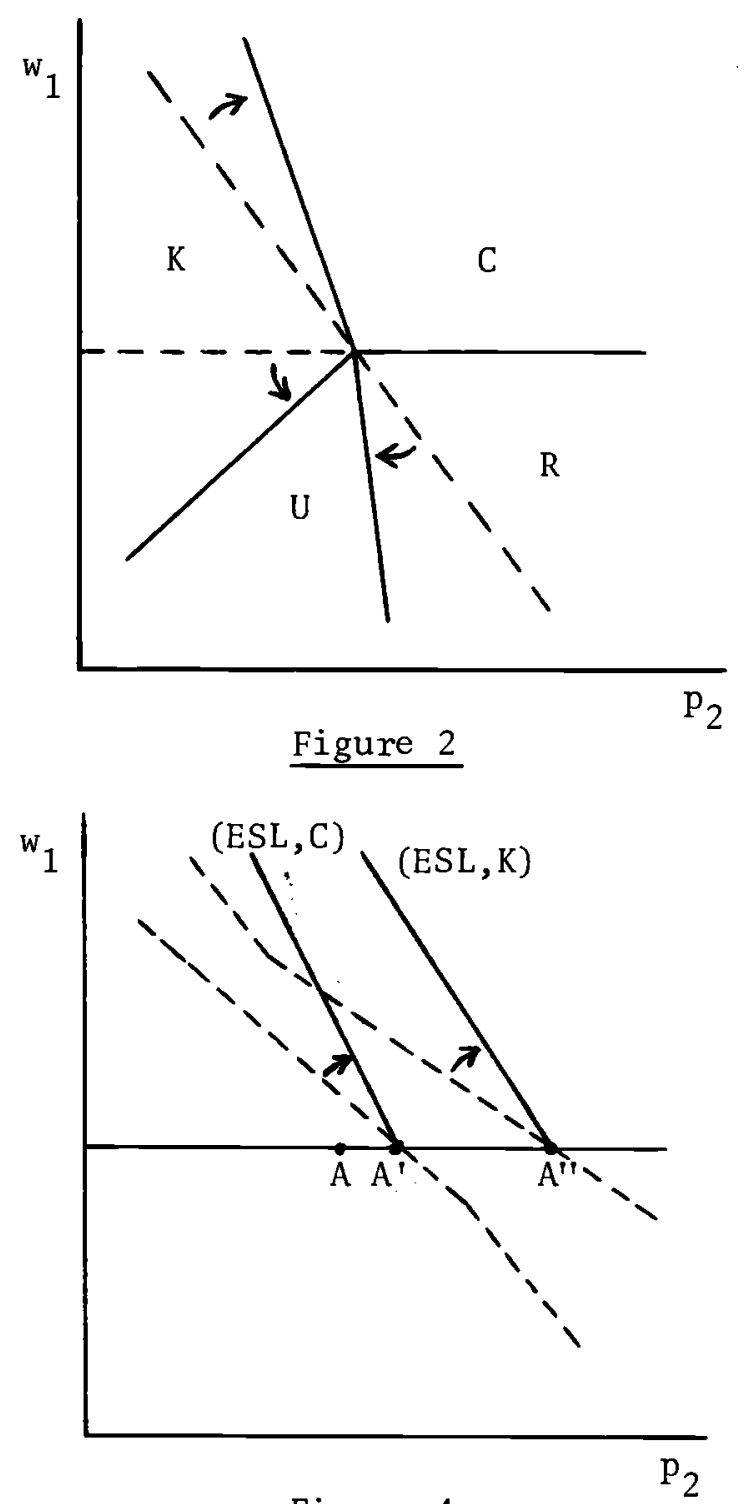

Figure 4

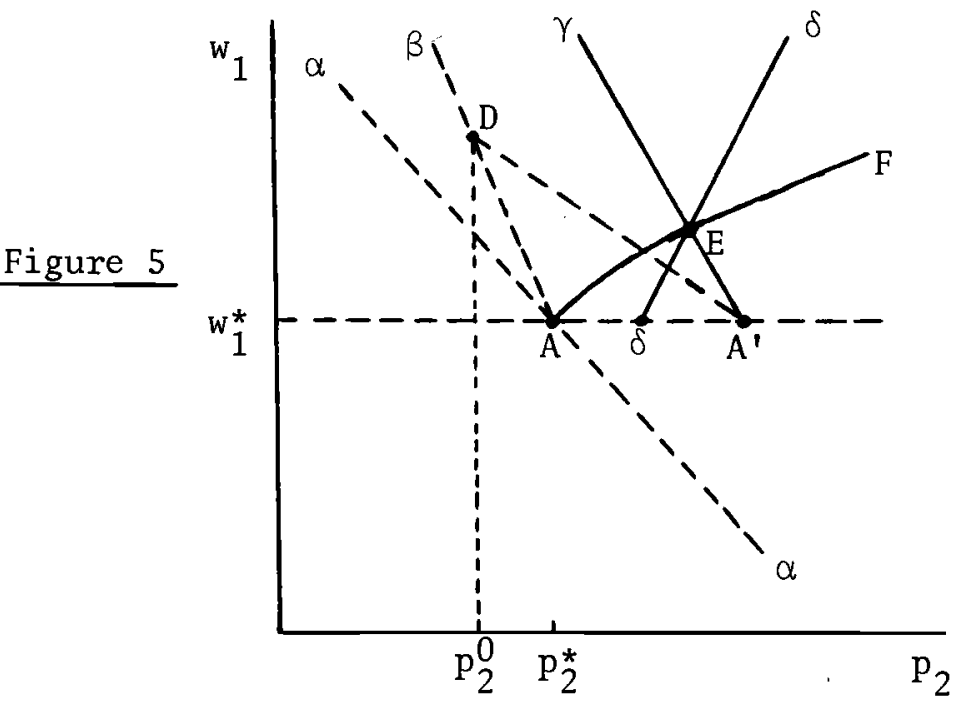



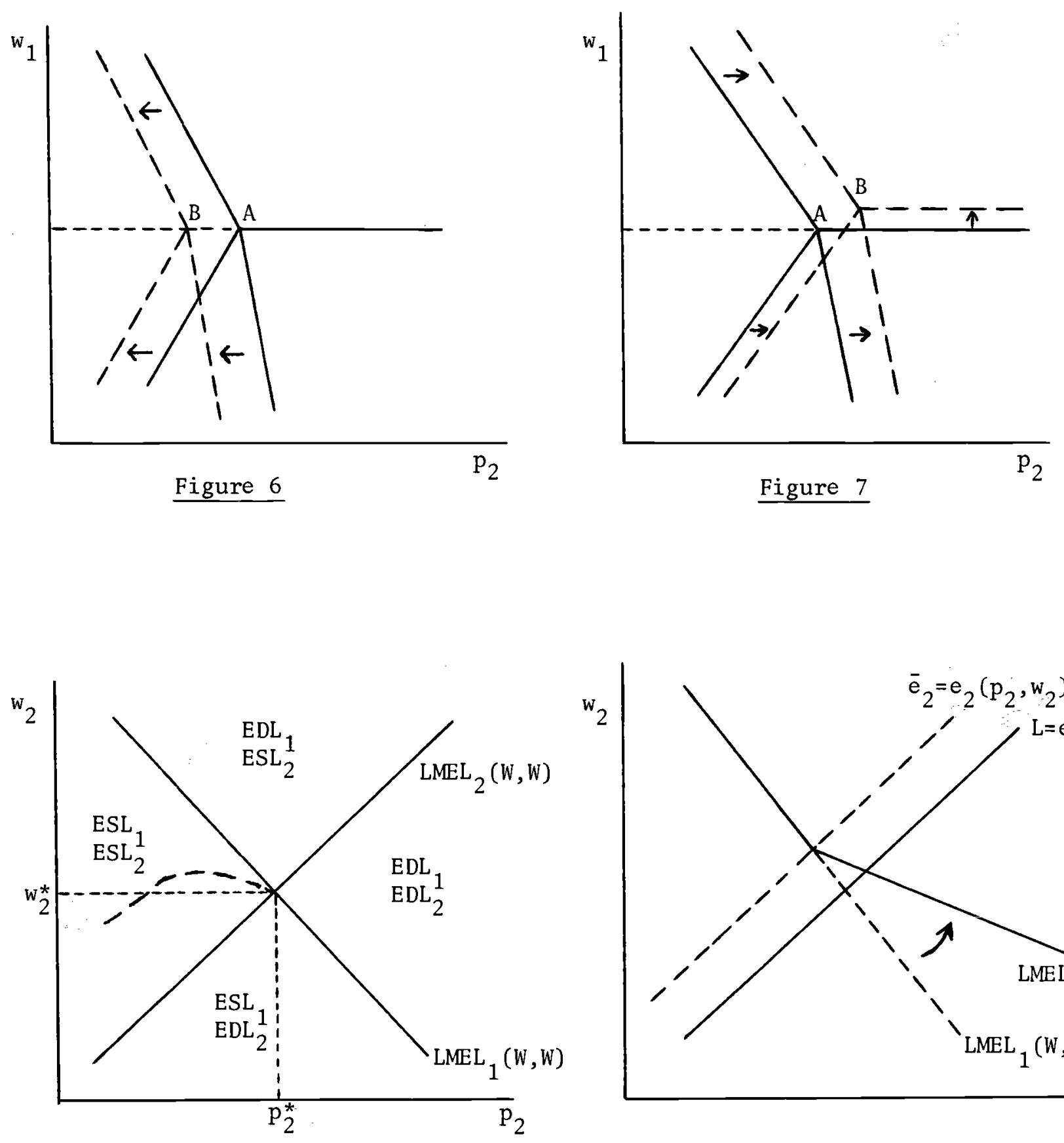

Figure 8

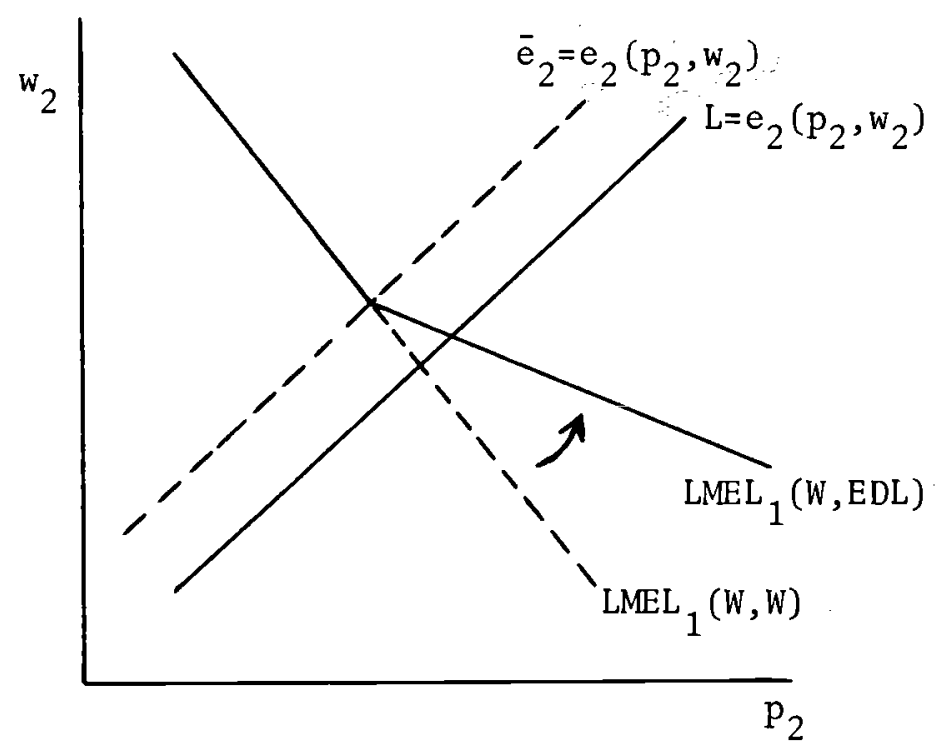

Figure 9 